\title{
ORIGINAL
}

ARTICLES

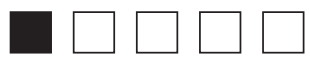

\section{A Publication Rate Comparison of Oral Communications Presented at the 2010 and 2015 French General Practice Congresses and European General Practice Network Meetings}

Maxime Pautrat, MD; Melissa Tenot, MD; Jean Pierre Lebeau, MD, PhD

\begin{abstract}
BACKGROUND AND OBJECTIVES: We sought to assess and compare the publication rates of research presented at two French general practice congresses (Collège National des Généralistes Enseignants (CNGE, National College of General Practice Teachers) and Congrès de la Médecine Générale de France (CMGF [French General Practice Congress]) and the European General Practice Research Network (EGPRN) meetings held in 2010 and 2015.
\end{abstract}

METHODS: We included all oral presentations from the 2010 and 2015 CNGE, CMGF and EGPRN meetings. We searched subsequent publications up to December 2018. We collected study themes, study designs, author qualifications, and journals for all published presentations.

RESULTS: Overall, we included 701 oral presentations; 33\% of the 2010 presentations, and $30 \%$ of the 2015 presentations were subsequently published $(P=.40)$. For both years, the overall publication rate was higher for presentations from the EGPRN meetings compared with the French meetings (55.6\% vs $27.1 \% ; P<.05)$. Published articles mostly concerned clinical research and quantitative methods from academic authors. Seventeen percent of articles from the EGPRN meetings were published by BMC Family Practice and the European Journal of General Practice, whereas 32\% of articles from the French meetings were published by Exercer, the French Journal of General Practice.

CONCLUSIONS: More than half of the presentations at the 2010 and 2015 EGRPN meetings were published, whereas the publication rate from the French meetings remained under $30 \%$. Further efforts are needed to increase the publication rate of general practice studies in peer-reviewed international journals.

(Fam Med. 2021;53(9):754-9.)

doi: 10.22454/FamMed.2021.447144

n 2008, the World Health Organization highlighted the need to develop research in primary care, ${ }^{1}$ and since then, a number of bibliometric studies, calls to action, and research agendas have been developed and published. ${ }^{2-4}$ However, general practice still needs to expand and update its scientific corpus through specific research. Research visibility and collaborative projects are therefore essential and strengthen the need for academic associations and scientific meetings.
In 1971, the European Branch of the World Organization of National Colleges, Academies and Academic Associations of General Practitioners/Family Physicians (WONCA Europe) gave rise to the European General Practice Research Workshop, which in turn became an independent network, the European General Practice Research Network (EGPRN). ${ }^{5}$ The EGPRN has organized two European meetings every year since 1974 . These meetings are exclusively dedicated to general practice/family medicine (GP/ FM) and primary health care (PHC) research. In 2009, the EGPRN published a European PHC research agenda that was translated into all European languages and widely distributed. ${ }^{4}$

It was only in the last decade that general practice gained full academic acknowledgement in France. The first academic general practice teachers were nominated as associate professors in 1991 and general practice finally gained full recognition as an academic specialty in $2004 .{ }^{6}$ In 2006 , primary care research officially

From the Department of General Practice (Dr Pautrat, Dr Tenot, and Dr Lebeau), and Department of Education, Ethics, and Health (Dr Pautrat and Dr Lebeau), University of Tours, France. 
became a concern for the French Minister of Health. ${ }^{7}$ The first tenured university professors of general practice were appointed in $2009,8,9$ and general practice teachers and researchers became members of a national college (Collège National des Généralistes Enseignants [CNGE]). ${ }^{10}$ Since 2007, all general practice professional organizations, unions, and academic and learned societies (including the CNGE) have been part of the College of General Practice ( $\mathrm{Col}$ lège de Médecine Générale [CMG]). ${ }^{11}$ In 2001, the CNGE started to hold national annual meetings covering various academic primary care subjects, particularly research and education, including educational science research..$^{12}$ The CMG began to hold annual national meetings in 2007 (Congrès de la Médecine Générale de France [CMGF]) with presentations and workshops on professional, corporate, and union issues. ${ }^{13}$ Meeting communications result in essential debates and suggestions, yet efforts should be made to publish research study results in scientific journals to ensure international research visibility for primary care.

The aim of this study was to assess and compare the publication rates of oral research communications presented at the 2010 and 2015 CMGF, CNGE, and EGPRN meetings.

\section{Methods}

We used a descriptive analysis to assess the publication rates of studies presented at the 2010 and 2015 CNGE, CMGF, and EGPRN meetings. The CNGE and CMGF meetings are both annual, while the EGPRN meeting takes place twice a year, therefore a total of eight meetings were analyzed.

\section{Inclusion and Exclusion Criteria}

We included all abstracts accepted for oral presentation at the 2010 and 2015 CNGE, CMGF, and EGPRN meetings and published in the official congress abstract book in this study. We also included scheduled presentations that were cancelled.
We excluded abstracts accepted for posters, workshops, and symposiums.

\section{Data Sources}

For presentations, we identified abstracts accepted for oral presentation from the original abstract book. We searched for relevant publications related to the presentations from the meeting date to December 2018 using MedLine (via PubMed) and the archives of two French general practice journals currently not indexed in MedLine (Exercer, the French Journal of General Practice (edited by the CNGE), and Médecine. Words from the presentation titles and lead authors' names were used as keywords. We compared abstracts of the selected published articles with the meeting presentation abstracts.

When no matching publication was found, we contacted the presentation lead author by email or phone and asked the following questions:

- Did you or anyone else publish these results after the meeting presentation?

- If so, when and in which journal?

We retrieved the academic status of the presenter at the time of the presentation and that of the publication lead author (if different) online or by asking the authors.

\section{Data Analysis}

For each included meeting presentation and publication, we recorded the following data:

- Main theme: epidemiological, clinical, or educational study

- Research design: qualitative or quantitative analysis or systematic review

- Journal: MedLine indexation status and Thomson Reuters impact factor

- Lead author: academic status

We searched for and removed duplicates. When a study was presented several times, only the meeting where the study was first presented was considered, and when a study was published several times, only the first publication was considered. For each meeting in 2010 and in 2015 , the publication rate was calculated by dividing the number of publications by the number of presentations.

We compared publication rates and characteristics using the $\chi^{2}$ test. A $P$ value $<.05$ was considered statistically significant. We performed all statistical analyses were performed using BiostaTGV (https://biostatgv. sentiweb.fr/).

\section{Results}

\section{Publication Rates}

Overall, there were 701 oral presentations at the 2010 and 2015 CNGE, CMGF, and EGPRN meetings (Table 1). We retrieved publication status (published or unpublished) for 582 (83\%) presentations. The total publication rate for these eight meetings was $31.8 \%$, with $33.4 \%$ in 2010 and $30.2 \%$ in $2015(P=.36)$.

The EGPRN meeting had a significantly higher publication rate compared with the CMGF meetings, CNGE meetings, or both $(55.6 \%$ vs $28.1 \%, 25.9 \%$, and $27.1 \%$, respectively; $P<.05$ for all). The EGPRN meeting publication rate was also significantly higher for each meeting year: $63.6 \%$ vs $27.2 \%$ (CNGE) and $28.1 \%$ (CMGF) in 2010, and $48.4 \%$ vs $24.8 \%$ (CNGE) and 28.0\% (CMGF) in $2015(P<.05$ for all).

The EGPRN meeting publication rate was not significantly different between 2010 and 2015 (63.6\% vs $48.4 \% ; P=.097$ ). There was no difference in publication rates between the two French meetings (CNGE and CMGF).

\section{Published Study Themes}

Overall, the publications most frequently addressed clinical issues, without significant difference between the French and European meetings: $51 / 80$ vs $24 / 35$; $(P=.94)$ in 2010 , and $61 / 76$ vs $20 / 30(P=.70)$ in 2015 (Figure 1).

Publication of educational themes decreased between 2010 and 2015, without significant differences between the French and the European meetings in 2010 (21/80 vs $9 / 35$, $P=.99)$ and in $2015(11 / 76$ vs $8 / 30$, $P=.35)$.

VOL. 53, NO. 9 • OCTOBER 2021 
Table 1: Publication Rates in 2010 and 2015 According to Meetings

\begin{tabular}{|c|c|c|c|c|c|c|c|}
\hline & \multicolumn{2}{|c|}{ CNGE } & \multicolumn{2}{|c|}{ CMGF } & \multicolumn{2}{|c|}{ EGPRN } & \multirow[t]{2}{*}{ Total } \\
\hline & 2010 & 2015 & 2010 & 2015 & 2010 & 2015 & \\
\hline Presentations (n) & 125 & 149 & 167 & 143 & 55 & 62 & 701 \\
\hline Publications (n) & 34 & 37 & 47 & 40 & 35 & 30 & 223 \\
\hline \multirow{2}{*}{ Publication rate (\%) } & 27.2 & 24.8 & 28.1 & 28.0 & 63.6 & 48.4 & \multirow{2}{*}{31.8} \\
\hline & \multicolumn{2}{|c|}{25.9} & \multicolumn{2}{|c|}{28.1} & \multicolumn{2}{|c|}{55.6} & \\
\hline
\end{tabular}

Abbreviations: EGPRN, European General Practice Research Network; CNGE, Collège National des Généralistes Enseignants; CMGF: Congrès de la Médecine Générale de France (French General Practice Congress).

$P$ values <.05 were:

- 2010: EGPRN vs CNGE

- 2010: EGRPN vs CMGF

- 2015: EGPRN vs CNGE

- 2015: EGPRN versus CMGF

- $2010+2015:$ EGPRN vs CNGE

- $2010+2015$ : EGPRN s CMGF

- 2010 + 2015: EGPRN vs CMGF + CNGE

All other differences were not significant.

Figure 1: Themes of Published Presentations at the 2010 and 2015 European and French General Practice Meetings

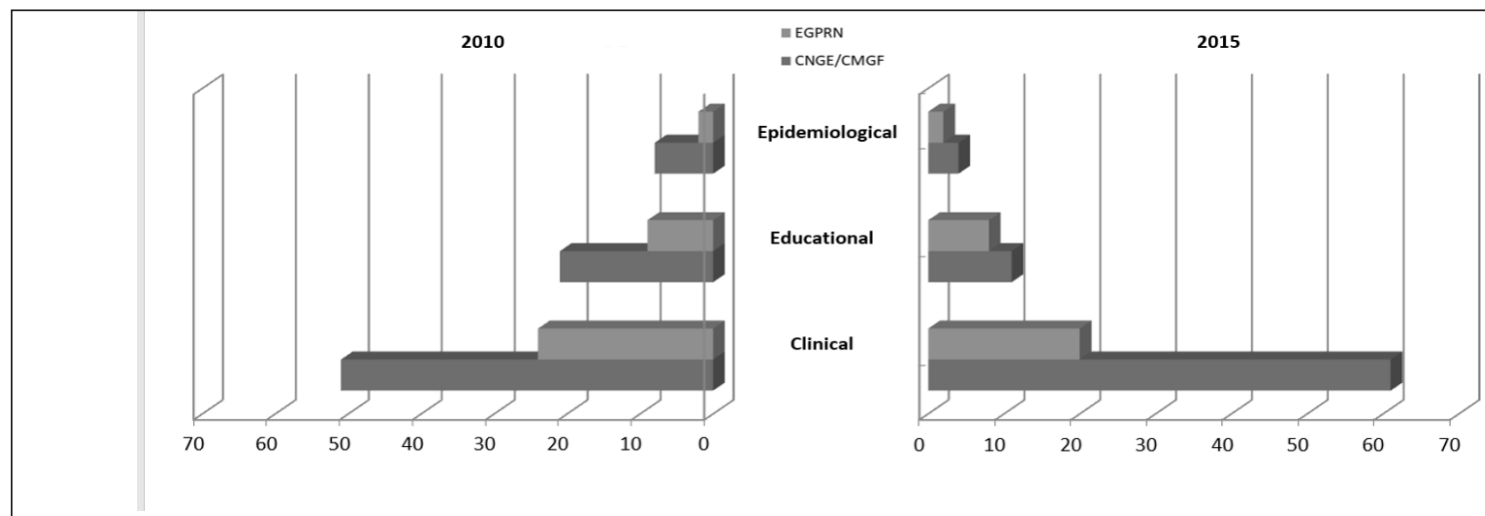

Abbreviations: EGPRN, European General Practice Research Network ; CNGE, Collège National des Généralistes Enseignants ; CMGF: Congrès de la Médecine Générale de France (French General Practice Congress)

\section{Research Design}

Research designs did not differ significantly between the EGPRN and the French meetings $(P=.72)$. Quantitative study presentations were more frequent, but the proportion of presented versus published studies seems better for qualitative studies, although not reaching significance (131/366 [35\%] vs 83/196 [42\%] $P=.31$ ). The number of published qualitative studies vs quantitative studies and systematic reviews decreased significantly for the two French meetings between 2010 and
2015 (39 [48\%] vs 42 [52\%], and 22 [28.5\%] vs 55 [71.5\%], respectively in 2010 and $2015 ; P=.01$ ). Quantitative studies were the most frequently published overall (59\%), and for each meeting (Table 2). There were few epidemiological study presentations but all those from the European meetings were subsequently published. Two-thirds of educational studies were presented at the CNGE meetings, and $28 \%$ were published $(\mathrm{n}=22)$. Notably, only one systematic review was published after presentation at the EGPRN meeting.

\section{Journals}

Figure 2 presents the journals according to the study methods, for the French and European meetings, in 2010 and 2015. The EGPRN meeting presentations were more frequently fully published in BMC Family Practice (seven publications) and the $\mathrm{Eu}$ ropean Journal of General Practice (EJGP, four publications), representing $17 \%$ of the total publications after the EGPRN meeting. However, the French meeting presentations were more frequently published in Exercer (n=50, representing 32\% of 
Table 2: Published Study Methods

\begin{tabular}{|l|c|c|c|c|c|c|c|}
\hline & \multicolumn{2}{|c|}{ CNGE } & \multicolumn{2}{c|}{ CMGF } & \multicolumn{3}{c|}{ EGPRN } \\
\hline \multicolumn{1}{|c|}{$\mathbf{n}(\%)$} & $\mathbf{2 0 1 0}$ & $\mathbf{2 0 1 5}$ & $\mathbf{2 0 1 0}$ & $\mathbf{2 0 1 5}$ & $\mathbf{2 0 1 0}$ & $\mathbf{2 0 1 5}$ & $21(70)$ \\
\hline Quantitative studies & $17(50)$ & $25(68)$ & $24(51)$ & $23(57)$ & $21(60)$ & $131(59)$ \\
\hline Qualitative studies & $17(50)$ & $8(22)$ & $22(47)$ & $14(35)$ & $14(40)$ & $8(27)$ & $83(37)$ \\
\hline Systematic reviews & 0 & $4(11)$ & $1(2)$ & $3(8)$ & 0 & $1(3)$ & $9(4)$ \\
\hline Total & 34 & 37 & 47 & 40 & 35 & 30 & 223 \\
\hline
\end{tabular}

Abbreviations : EGPRN, European General Practice Research Network ; CNGE, Collège National des Généralistes Enseignants ; CMGF: Congrès de la Médecine Générale de France (French General Practice Congress).

$P$ value <.05: 2010 (CMGF + CNGE), qualitative studies vs quantitative and systematic reviews.

All other differences were not significant.

Figure 2: Journals According to the Study Methods for the 2010 and 2015 French and European Meetings

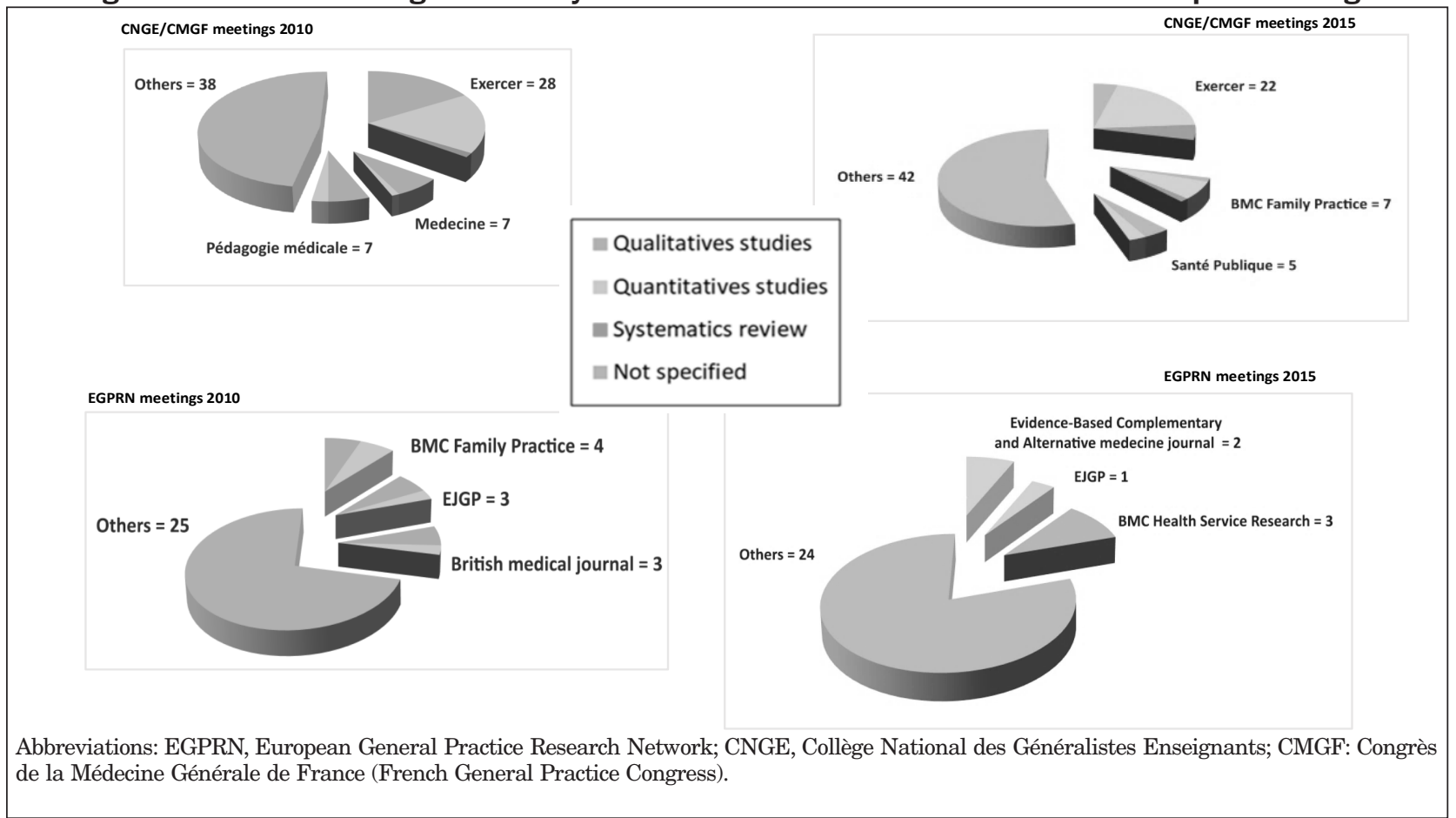

the total publications). The remaining 162 articles were published by 105 different journals.

\section{Authors}

Publication lead authors were mainly academics with similar proportions between 2010 and 2015 (59.9 vs $59.8 \%$ and 50.8 vs $48.9 \%$, for the French and European meetings, respectively; (Figure 3). However, the number of publication lead authors working as senior registrars (resident physicians) and assistants (interns) increased significantly between 2010 and 2015 for the French meetings: $25.3 \%(\mathrm{n}=20)$ vs $64.0 \%$ ( $\mathrm{n}=32 ; P<0.05)$. The number of lead authors working as professors did not significantly decrease between 2010 and 2015 (16/33 vs 9/27, respectively) for EGPRN meetings $(P=0.44)$ or French meetings (53/99 vs $36 / 82$, respectively; $P=.45$ ).

\section{Discussion}

We found that the publication rate of oral communications presented at the French and European GP/ FM meetings was approximately
$30 \%$ and remained stable between 2010 and 2015. This overall rate was similar to the publication rates from other specialty meetings such as cardiology (30\%), ${ }^{14}$ radiology (29\%$47 \%),{ }^{15-18}$ orthopedics (33\%-59\%), ${ }^{19-22}$ and gastroenterology $(31 \%-58 \%){ }^{23}$

According to a previous study, the publication rate of studies presented at the EGPRN meetings between 1999 and 2006 was found to be $45.0 \%,{ }^{24}$ which is concordant with the rate of $48.4 \%$ that we found for the 2015 EGPRN meetings. This overall publication rate is similar 
Figure 3: Publication Lead Author Positions in 2010 and 2015 According to the French and European Meetings

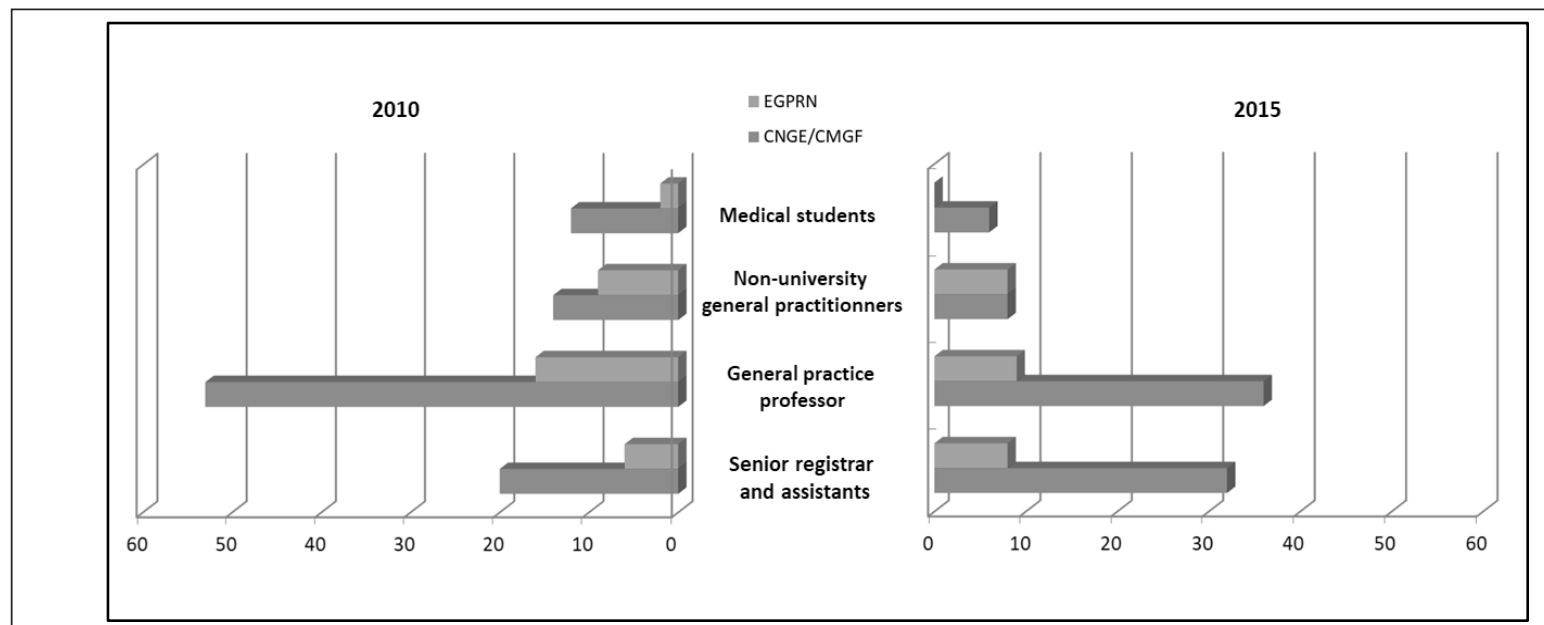

Abbreviations: EGPRN, European General Practice Research Network; CNGE, Collège National des Généralistes Enseignants; CMGF: Congrès de la Médecine Générale de France (French General Practice Congress).

to those for North American primary care meetings, where $47.3 \%$ of oral presentations at the Society of Teachers of Family Medicine and North American Primary Care Research Group meetings in 20072008 were eventually published..$^{25}$ In a study on oral presentations at the 2009 and 2011 Nordic Congresses of General Practice, $42.5 \%$ were subsequently published. ${ }^{26}$ This publication rate is higher than the rate of $27.1 \%$ found for the French national meetings in the present study. However, the Nordic Congress gathers four Scandinavian countries, and the higher publication rate could be explained by a larger number of researchers. These publication rates after primary care and medicine meetings confirm the gradual increase seen over the last 3 decades (8.5\% in $1999,20.9 \%$ in 2009 , and $>30 \%$ in 2015). ${ }^{27}$

We found a higher publication rate for European (EGPRN) than national (CNGE and CMGF) meetings. A possible explanation is the higher mean academic level of authors (and attendees) at EGPRN meetings. Interns and trainees, for instance, are more likely to present their research studies or thesis work on their own at a national meeting, whereas a forthcoming $\mathrm{PhD}$ student would rather present an international research team project at the EGPRN meeting. This explanation would be consistent with the findings of Post et al..$^{25}$

Another explanation for the discordant publication rates is the difference between the respective scopes of the meetings. EGPRN meetings are only research meetings. However, in the French meetings, research study presentations are scheduled alongside other presentations and workshops on legal, financial or corporate issues, medical teaching and continuing medical education, career opportunities, and union representations.

Furthermore, submitted abstract selection is believed to be stricter for the EGPRN meeting than for French meetings meaning these studies may have a greater chance of being accepted for publication.

We found that studies presented at the EGRPN meetings were more frequently published in BMC Family Practice and the European Journal of General Practice, which is reasonable as they are both considered the main journals for publication of studies presented at these meetings. In our study, one-third of presentations at the 2010 and 2015 CNGE or CMGF meetings were published in journals not indexed in the National Library of Medicine.

Analyzing the GP/FM publication trends over the last decade reveals increasing numbers since 2009 , when the first generation of junior academics in general practice started to publish their research..$^{28}$ Before then, a majority were collaborating with specialized research teams, so were more likely to submit their abstracts for presentation at other specialty meetings rather than GP/FM meetings. Our results appear to reveal a "communicating vessels" type effect occurring between 2010 and 2015 with a rise in publications from junior academics and decreased publications from their mentors and supervisors.

Our study has several limitations. The initial search of the meeting abstract books was done manually, and some publications may have been omitted, although all lead authors were also contacted. To limit this bias, the words in the titles of the presentations and the names of all authors were used as keywords in the databases, not just the first presenter as has been done in other similar studies. We retrieved full data for $83 \%$ of the presentations, which was higher than the previous survey by Van Royen et al, who used questionnaires to assess publication rates of studies presented at the EGPRN meetings between 1999 and $2006 .{ }^{24}$ We calculated publication rates using the total number of presentations, meaning any missed publication of a presentation would affect the rate. However, presentations for which we did not retrieve 
any data were unlikely to have been published. Secondly, studies presented in the 2015 meetings may have still been in the process of publication at the end of follow-up in 2018. However, 3 years is usually considered a sufficiently long period between a meeting presentation and full publication..$^{14-23}$ Thirdly, we did not retrieve data to analyze how academic research teams affect publication rates. Finally, we can only assume there is a difference in abstract selection between the EGPRN and French meetings.

To our knowledge, this is the first study to compare the publication rates of oral communications between French national and European meetings. The quality of this study also resides in the restriction to oral presentation abstracts, which scientific meeting committees usually consider to be the most relevant and highest-quality studies. This choice is consistent with the higher publication rate following an oral presentation at a primary care meeting compared with a poster. ${ }^{25} \mathrm{We}$ also analyzed full abstracts from meetings booklets analyzed to assess unpublished presentation methods and themes to avoid double counting and limit measurement bias.

\section{Conclusion}

GP/FM publication rates following presentation at French and European meetings were found to be similar to other specialties. However, only one-third of presentations were published, which raises several issues. Further qualitative studies assessing the reasons why studies were unpublished may help to improve the publication rate in primary care.

ACKNOWLEDGMENTS: The authors thank Professor Denis Angoulvant, Patrick Vourc'h (University of Tours), and Dr Marc Jamoulle (Charleroi) for their contributions and revision. This study is part of the French network of University Hospitals HUGO (Hôpitaux Universitaires du Grand Ouest). Editorial assistance in the preparation of this article was provided by Charlotte Wright BVM\&S (Hons) MRCVS DipTrans of Speak the Speech Consultancy.

PRESENTATIONS: This study was presented at the 86th the EGPRN Meeting, in May 2018, Lille, France.
CORRESPONDING AUTHOR: Address correspondence to Dr Maxime Pautrat, Université de Tours, faculté de médecine, 10 boulevard Tonnellé, 37000 Tours, France. 02.47.36.60.19. maxime.pautrat@univ-tours.fr.

\section{References}

1. World Health Organization. Primary Health Care - Now More Than Ever. Geneva: WHO; 2008.

2. Odorico M, Lalande S, Le Goff D, et al. A research agenda for French research in general practice. Exercer. 2018;141:112-20.

3. Glanville J, Kendrick T, McNally R, Campbell J, Hobbs FD. Research output on primary care in Australia, Canada, Germany, the Netherlands, the United Kingdom, and the United States: bibliometric analysis. BMJ. 2011;342(mar08 2):d1028. doi:10.1136/bmj.d1028

4. Hummers-Pradier E, Beyer M, Chevallier P, et al. The Research Agenda for General Practice/ Family Medicine and Primary Health Care in Europe. Part 1. Background and methodology. Eur J Gen Pract. 2009;15(4):243-250. doi:10.3109/13814780903452184

5. European General Practice Research Network (EGPRN). Accessed June 17, 2021. https://www. egprn.org/.

6. Order of September 22, 2004 establishing the list and regulation of diplomas in specialized medical studies.

7. De Pouvourville G. Développer la recherche en médecine générale et en soins primaires en France. Rapport remis aux Ministres de la Santé et de la Recherche, mai 2006.

8. Taha A, Boulet P, Beis JN et al. Current situation of academic General practice on January 1, 2015: internal construction of the General practice academic sector. Exercer. 2015.122:267-82.

9. Decree number 2008-744 of July 28, 2008 laying down provisions relating to university teaching staff, holders and non-holders of general medicine.

10. Collège National des Généralistes Enseignants (CNGE). Accessed June 17, 2021. https://www. cnge.fr/.

11. Le Collège de la Médecine Générale. Accessed June 17, 2021. https://lecmg.fr/.

12. CNGE National Congress. Accessed June 17, 2021. https://www.congrescnge.fr/.

13. French General Practice Meeting. Accessed June 17, 2021. https://www.congresmg.fr/fr/.

14. Chand V, Rosenfeldt FL, Pepe S. The publication rate and impact of abstracts presented at the Cardiac Society of Australia and New Zealand (1999-2005). Heart Lung Circ. 2008;17(5):375-379. doi:10.1016/j. hlc.2008.02.005

15. Arrivé L, Boelle PY, Dono P, Lewin M, MonnierCholley L, Tubiana JM. Subsequent publication of orally presented original studies within 5 years after 1995 RSNA Scientific Assembly. Radiology. 2004;232(1):101-106. doi:10.1148/ radiol.2321030819

16. Bydder SA, Joseph DJ, Spry NA. Publication rates of abstracts presented at annual scientific meetings: how does the Royal Australian and New Zealand College of Radiologists compare? Australas Radiol. 2004;48(1):25-28. doi:10.1111/ j.1440-1673.2004.01243.x
17. Miguel-Dasit A, Martí-Bonmatí L, Sanfeliu P, Aleixandre R. Scientific papers presented at the European Congress of Radiology 2000: publication rates and characteristics during the period 2000-2004. Eur Radiol. 2006;16(2):445450. doi:10.1007/s00330-005-2861-3

18. Secil M, Ucar G, Dicle O. Scientific papers presented at the 2000-2001 European Society of Gastrointestinal and Abdominal Radiology (ESGAR) meetings: publication rates during the period 2000-2004. Eur Radiol. 2007;17(8):2183-2188. doi:10.1007/s00330-0060297-z

19. Guryel E, Durrant AW, Alakeson R, Ricketts DM. From presentation to publication: the natural history of orthopaedic abstracts in the United Kingdom. Postgrad Med J. 2006;82(963):70-72. doi:10.1136/ pgmj.2005.033738

20. Jasko JJ, Wood JH, Schwartz HS. Publication rates of abstracts presented at annual musculoskeletal tumor society meetings. Clin Orthop Relat Res. 2003;415:98-103. doi:10.1097/01. blo.0000093902.12372.76

21. Kleweno CP, Bryant WK, Jacir AM, Levine WN, Ahmad CS. Discrepancies and rates of publication in orthopaedic sports medicine abstracts. Am J Sports Med. 2008;36(10):18751879. doi: $10.1177 / 0363546508319054$

22. Kwong Y, Kwong FN, Patel J. Publication rate of Trauma abstracts presented at an International Orthopaedic conference. Injury. 2007;38(7):745-749. doi:10.1016/j.injury.2006.07.002

23. Hopper AD, Atkinson RJ, Razak A, et al. Is medical research within the UK in decline? A study of publication rates from the British Society of Gastroenterology from 1994 to 2002. Clin Med (Lond). 2009;9(1):22-25. doi:10.7861/ clinmedicine.9-1-22

24. Van Royen P, Sandholzer H, Griffiths F, et al. Are presentations of abstracts at EGPRN meetings followed by publication? Eur J Gen Pract. 2010;16(2):100-105. doi:10.3109/138147 88.2010.482582

25. Post RE, Mainous AG III, O'Hare KE, King DE, Maffei MS. Publication of research presented at STFM and NAPCRG conferences. Ann Fam Med. 2013;11(3):258-261. doi:10.1370/afm.1503

26. Waldorff FB, Petersen K, Vinther S, Sandholdt H, Siersma V, Andersen JS. Full journal publication of abstracts presented at the Nordic Congress of General Practice in 2009 and 2011. Scand J Prim Health Care. 2017;35(1):84-88. doi:10.1080/02813432.2017.1288820

27. Post RE, Weese TJ, Mainous AG III, Weiss BD. Publication productivity by family medicine faculty: 1999 to 2009 . Fam Med. 2012;44(5):312-317.

28. Hajjar F, Saint-Lary O, Cadwallader JS, et al. Development of Primary Care Research in North America, Europe, and Australia From 1974 to 2017. Ann Fam Med. 2019;17(1):49-51. doi:10.1370/afm.2328 